\title{
Issues and Challenges Social Insurance in Malaysia
}

\author{
M.Z.A. Chek, I.L. Ismail \\ Center for Actuarial Studies, Universiti Teknologi MARA, Perak Branch \\ DOI: https://dx.doi.org/10.47772/IJRISS.2021.5410
}

\begin{abstract}
Social insurance programmes differ from private insurance in several ways. Firstly, the contributions are normally compulsory and may be made by the insured's employer, by the state, as well as by the insured himself. Benefits are also not as strictly tied to contributions as is the case with private insurance. For example, to make the programmes serve certain social purposes, some contributors are included among the beneficiaries even though they may not have contributed for the required period of time. Next, benefits may be increased in response to the rising cost of living, which reduce the amount between contributions and benefits. The main objective of this study is to discuss and describe the current issues and challenges of social insurance qualitatively.This method provides an overview of further understanding pertaining to the phenomena faced by Social Security Organisation (SOCSO) as administer social insurance in Malaysia.
\end{abstract}

Keywords - Social Insurance, SOCSO, Contribution, Benefits, Malaysia

\section{INTRODUCTION}

$\mathrm{M}$ any developing countries are in the process of improving their social security while having made efforts in implementing social financing reforms. Some countries have been attempting to advance even further toward the ultimate goal of universal health insurance coverage.

Malaysia is no exception, to this progress and have been made the government's attempt to expand the coverage of social security in Malaysia [1]-[3]. Since then, SOCSO's management has placed further emphasis on this issue and it now has a grand design and time line to achieve this objective leading to an expanded social security coverage by 2025 [4][6]. Hence, various dynamic changes have occurred in the social security system of Malaysia in recent years[4], [7][10].

\section{SOCIAL SECURITY PRINCIPLES}

In Malaysia, SOCSO is mandated to administer and enforce the Employee Social Security Act 1969 (the Act) and Employee Social Security General Regulations 1971 (Regulations). Through the Act and Regulations, SOCSO is able to provide free medical treatment, facility for physical or vocational rehabilitation, and financial assistance to employees who have suffered from accidents or diseases that have taken away or reduced their ability to work or rendered them incapacitated. If an employee dies, their dependents are financially supported through pensions [11]. In fulfilling its responsibilities, SOCSO is guided by three core principles, as follows:

\section{A. $\quad$ Solidarity Fund}

Solidarity is the cardinal value of social protection. In practice, it is a series of mechanisms for the redistribution of income to people who are disabled or invalid and families with dependent children. Generally, contributions made by SOCSO members to SOCSO are channelled to the solidarity fund. The determining factor when calculating the quantum for an employee's contribution is based on his or her monthly salary. Through this understanding, employees share the same level of exposure and risk regardless of the industry in which they work.

The sharing of risk in this context brings the understanding that all contributors agree and are united in allowing SOCSO to use the solidarity fund to pay benefits to employees who have suffered disability or invalidity and to pay pension to dependents in the case of death. For employees who have not received any benefits until retirement, they are actually helping other employees who suffer from disabilities or invalidity and helping families who have lost family members due to death. In the long-term, this may also happen to their own families. On top of that, the retiree's and other contributor's contributions are also used to help their families based on the core principles of 'solidarity fund'.

\section{B. $\quad$ Replacement of Income}

This principle applies when determining the amount of benefit payments. It is related to the amount of contributions paid based on the employees' salary. This concept is to ensure that the employees would not be financially affected if they have disabilities or invalidity. In the case of death of an insured person, replacement of income is provided to the dependents in the form of monthly pensions.

\section{Equality}

The fundamental basis of this principle is inherent within the Act and Regulation itself. By virtue of the concept of social justice, the coverage of the scope must encompass all employers and employees registered with SOCSO. Through this concept, prevention of accidents with the objective of zero accident and fostering a culture of healthy lifestyle should be implemented because the real aim of social security is to keep employees in the workforce until they retire.

If this can be done, the real income of an employee would be higher, in line with the new economic model that focuses on high income society. This concept also provides space and opportunity for a motivated employee to return to work. In 
addition, rehabilitation is also given to employees who suffer disability and invalidity.

\section{ISSUES AND CHALLENGES OF SOCIAL INSURANCE IN MALAYSIA (SOCSO)}

From the experiences of advanced countries, designing a social security system that is robust in the initial stage is crucial because an institution such as a social security system could become permanent and many advanced countries are now suffering from difficult public healthcare reforms in terms of how to contain increasing invalidity pension related expenses that jeopardizes financial sustainability. This local case study will benefit other developing and emerging countries as well (Valdiavia, 1997; Gruber and Wise, 1998; ILO, 2001; Herce, 2003; Aline Grunewald, 2014). The current issues in social security in Malaysia are as follows:

\section{A. Demographic and Life Expectancy}

Social issue can be seen in depth through the national population growth rate [17], [18]. The impact of this population growth rate will affect social security from the angle of poverty eradication, expansion of the scope of social security protection, poverty among senior citizens and the problem of increasing life expectancy [19]-[21] . Based on the national population in the year 2013, the total population is about 29.95 million with the average life expectancy of males being about 72.6 years and females about 77.2 years [22].

The number of citizens who are 65 and above is now about 1.65 million $(5.50 \%)$ and this number is expected to increase to 4.41 million (11.4\%) in the year 2040. Malaysia is expected to experience an aging population in 2021 when the population aged 65 years and above reaches $7.1 \%$ (Aziz, 2012; Mitchell et al., 2013). Social security challenge is to ensure that the sustainability of the fund can continue to accommodate the increase in life expectancy in which the number of beneficiaries and monthly pension payments will increase [19], [25] .

\section{B. Financial System}

From the financial percpective, the sustainability of social security fund depends on several factors, such as:

\section{1) ROI of SOCSO}

The instability of the world economy which can affect the Returns On Investment (ROI). SOCSO expects that real return on investment (Real ROI) will remain weak compared to the last few years as the In-House portfolios remain focused on blue chips stocks. The KLCI was uncertain as a result of quantitative easing by United States of America (U.S.A.) and it led to an outflow of foreign funds from Malaysia (Yusoff et al., 2000).However, SOCSO's Fund is expected to continue to grow and will result in a surplus of RM24.2 billion in the year 2016. Overall, SOCSO's financial position is expected to continue to be strong for the next five years. In addition, it introduced a minimum wage and it will bring a positive impact to the SOCSO's Employment Injury Scheme (EIS) Fund [27].

2) Expenditure of SOCSO

A higher expenditure growth rate than the revenue growth rate, for instance, the cost of managing the Rehabilitation Centre in Melaka and the new ICT Project (PINTAR) is expected to contribute to a significant increase in SOCSO's operating expenditure [28]. In addition, SOCSO (2013) stated through its SWOT analysis that to indicate further expenditure to manage all 46 offices throughout the country.

Additionally, deficiency in the fund is also due to difficulty in tracing event employees located in inaccessible rural locations, unregistered employees and dormant employers. However, the cash flow of contributions to be collected can be influenced by efficient enforcement in collecting contributions from errant employers (defaulters) and ensuring all eligible employers are registered and pays their contribution by providing sufficient number of Inspectors to carry out inspections on the employer [29].The Ninth Actuarial Study projected the need to increase the contribution rate for the Invalidity Scheme by $0.5 \%$ based on Actuarial Valuation and Study conducted by ILO. Currently, this deficit is mitigated through the excess of income from the Employment Injury Scheme. SOCSO's fund as a whole remains satisfactory. The Employment Injury Scheme is a fully funded scheme which all contribution come from employer. However, the Invalidity Scheme is a partially funded scheme which is both $50 \%$ will contribute by employer and employee (SOCSO, 2014d) .

The fund position which remains sustainable allows SOCSO to approve certain improvements such as increasing the eligibility age for the Invalidity Scheme from 60 to 65 years, fixing the Constant attendance Allowance to RM500 monthly and fixing the minimum daily rate to RM30 from RM10 effective 1 January 2014 in line with the decision of the government to introduce a National Minimum Wage Policy [27].

\section{3) Managing Claims Process}

In 2013, a total of 106,093 cases were paid out of the 120,679 cases received. SOCSO managed to pay $99 \%$ of all cases within the time period stipulated in its Client Charter. It was also found that the average number of days taken for processing benefit cases was generally reduced in comparison to the previous year. There is however room for improvement in processing cases of reimbursement for medical bills [30].

\section{4) Managing Overall Risks}

SOCSO is also exposed to property safety risks in terms of fire and theft and other disasters such as flood and deposition of soil which may need particular attention especially to the buildings owned by SOCSO. The flood in Kemaman on $30^{\text {th }}$ December 2013 has tested the ability of SOCSO to implement its Disaster Recovery Plan to restore the operations of Kemaman SOCSO office in a short period of time. SOCSO also need to protect its computers and network from unauthorised access. Attention is also needed to ensure that 
there is no loss of data when data is transferred to the new operating system (SOCSO, 2014; Rohaizat et al., 2012).

\section{5) Delivery System}

SOCSO has always emphasized occupational safety and health issue by seeking to integrate its activities as part of daily work management. The issue of the delivery system on Occupational Safety and Health Management would ensure a culture of occupational safety and health for all its employees, customers and general public who deal with SOCSO is observed systematically.

In addition, the ICT Security Policy consists of all the guidelines and conditions for use of ICT assets. It is understood that visitors and third party usage of the ICT assets signifies that the users have read, understood and agree to the guidelines and conditions set by SOCSO. The policy explains that all users have responsibilities and roles in the protection and proper usage of the SOCSO ICT assets. Furthermore, SOCSO is committed to fulfilling customers' satisfaction through continuous improvement efforts in the delivery system [29].

\section{CONCLUSION}

In conclusion, social insurance in Malaysia is considered as one of the dynamic concepts of modern age which is influencing social as well as economic policy. Social insurance also the most effective weapon of peace. It is the security that the state furnishes against the risks which as individual of small means cannot stand up by himself or even in private combination with his fellows. This study originally signifies the issues and challenges measures during the period when wage earning capacity of a worker is adversely affected during sickness industrially disability, unemployment or old age. On top of that, SOCSO as government agency who administer the social insurance in Malaysia has attempts to execute benefit payments as fast and as accurately as possible. Additionally, the payment of benefits ismade to eligible employees or dependents under the Act and Regulations. This is to ensure that fairness and equality to all employees are achieved. In the spirit of fairness, the service is rendered with the aim to please the customers and to go beyond their expectations.

\section{ACKNOWLEDGEMENT}

This study was partially supported by UiTM Perak Branch. We thank our colleagues from Universiti Kebangsaan Malaysia (UKM) and Social Security Organisation (SOCSO) who provided insight and expertise that greatly assisted the study. We thank Prof. Dr. Zuriah Ab. Rahman for assistance, and Prof. Dr. Nuriszura Ismail for comments that greatly improved the manuscript.

\section{REFERENCES}

[1]. S. C. Seng, "Social Security: Concept and reality with reference to Malaysia SOCSO," Malaysia Labour Rev., vol. 1, no. 1, 2006.

[2]. S. C. Seng, "Social Security: Challenges and issues," Kuala Lumpur, 2014-1, 2014.

[3]. R. Holzmann, "Nonfinancial defined contribution schemes in a changing pension world: Overview and volume 1; Progress, lessons and implementation," Kuala Lumpur, 2012.

[4]. M. Z. A. Chek, I. L. Ismail, and N. F. Jamal, "Descriptive research on SOCSO's Invalidity Pension Scheme (IPS) claims payment," Int. J. Recent Technol. Eng., vol. 8, no. 2 Special Issue 11, pp. 660-663, 2019.

[5]. M. Z. A. Chek, I. L. Ismail, and N. F. Jamal, "Assessing Contribution Collection: A Case of SOCSO's IPS," Int. J. Recent Technol. Eng., vol. 8, no. 2S11, pp. 621-623, 2019.

[6]. M. Z. A. Chek, I. L. Ismail, and N. F. Jamal, "Descriptive Analysis of Trends in Frequency of Invalidity Pension Scheme (IPS) in Malaysia," Multidiscip. Informatics J., vol. 1, no. 1, pp. 53-61, 2018.

[7]. I. L. I. Azizah M., Noorizam D., Zaki A. C., Syazreen S., Final Report: Study on fatal accidents covering for the SOCSO contributors for the year 2007- 2009, 1st ed. Kuala Lumpur: RMI UiTM SHAH ALAM, 2009.

[8]. A. N. A. A. Ridzuan, M. Z. A. Chek, N. M. A. Ghafar, and A. B. Ahmad, "Developing an Introduction to Actuarial Science MOOC," Int. J. Acad. Res. Bus. Soc. Sci., 2018.

[9]. M. Z. A. Chek, I. L. Ismail, and N. F. Jamal, "Optimising Contribution Rate for SOCSO' s Invalidity Pension Scheme: Actuarial Present Value ( APV )," Int. J. Eng. Technol., vol. 7, pp. 83-92, 2018.

[10]. A. N. A. A. Ridzuan, M. Z. A. Chek, N. M. A. Ghafar, and A. B. Ahmad, "Developing an Introduction to Actuarial Science MOOC," Int. J. Acad. Res. Bus. Soc. Sci., vol. 8, no. 1, pp. 600605,2018

[11]. Malaysian Government, Employees' Social Security Act 1969, no. January. Kuala Lumpur: The Commissioner of Law Revision, Malaysia, 2006.

[12]. V. H. Valdiavia, "The insurance role of Social Security: Theory and lessons for policy reform," United States, 1997.

[13]. J. Gruber and D. Wise, "Social security and retirement: An international comparison," Am. Econ. Rev., vol. 88, no. 2, pp. 158$163,1998$.

[14]. ILO, Social security: Issues, challenges and prospects, 1st ed. Geneva: International Labour Office Geneva, 2001.

[15]. Aline Grunewald, "Social security around the world a review of datasets," 2014.

[16]. J. A. Herce, "Modelling the pension system," Futures, vol. 35, no. 1 , pp. 75-87, 2003.

[17]. L. K. Chee, "The Malaysian Government Pension Scheme: Whither its future direction?," J. Econ. Malaysia, vol. 31, pp. 87106, 1997.

[18]. K. Caraher, "Issues in incomes provision for the elderly in Malaysia," in Conference on Social Security, 2000, no. September, pp. 25-27.

[19]. H. Yamabana, "New approaches to extending social security coverage," in ISSA Meeting of Directors of Social Security Organizations in Asia and the Pacific, 2005, vol. 4, no. November, pp. $1-11$.

[20]. E. James, "Reforming social security : Lessons from 30 countries," Central Europe, 2005. [Online]. Available: www.ncpa.org/pub/st/st277. [Accessed: 20-Feb-2015].

[21]. J. Kubíček, "Contribution rates to funded pension systems in the new member countries," Res. Int. Bus. Financ., vol. 19, no. 2, pp. 266-280, 2005.

[22]. U.S. Social Security Administration, "Social Security Programs Throughout the World: The Americas, 2013," vol. 13-11804, no. 13, p. 203, 2014.

[23]. D. Mitchell, P. Brockett, R. Mendoza-Arriaga, and K. Muthuraman, "Modeling and forecasting mortality rates," Insur. Math. Econ., vol. 52, no. 2, pp. 275-285, 2013.

[24]. N. S. A. Aziz, "Case Study: The valuation of adequacy rate of contribution in the malaysia armed forces pension scheme using actuarial methods," Shah Alam, 2012.

[25]. H. Yamabana, "Latest development in global pension system," Kuala Lumpur, 2012.

[26]. M. B. Yusoff, F. A. Hasan, and S. A. Jalil, "Globalisation , economic policy, and equity: The case of Malaysia," OECD 
Development Center, 2000. [Online]. Available: http://www.oecd.org/dataoecd/54/49/2682426.pdf. [Accessed: 01Jan-2015].

[27]. ILO, "The 9th Actuarial Valuation Report," Bangkok, 2013

[28]. SOCSO, "SOCSO Annual Report 2012," Kuala Lumpur, 2013.

[29]. SOCSO, "SOCSO Annual Report 2014,” Kuala Lumpur, 2015.
[30]. SOCSO, “SOCSO Annual Report 2013,” Kuala Lumpur, 2014.

[31]. B. Y. Rohaizat, M. O. N. M. Hassan, and J. Davis, "Approaches and future direction of Social Security System: Malaysian perspective," Malaysian J. Public Heal. Med., vol. 12, no. 1, pp. $1-13,2012$. 